\title{
ANÁLISE DA ABORDAGEM SOCIOECONÔMICA NO CONTEXTO DO LICENCIAMENTO AMBIENTAL DE EMPREENDIMENTOS SUCROENERGÉTICOS NO ESTADO DE MATO GROSSO DO SUL
}

\author{
Analysis of social-economic approach in the context of \\ environmental licensing of sugar cane industries ventures in the \\ state of Mato Grosso do Sul
}

\author{
Izabela Cristina Prado Souza Barbosa Ronda Paiva \\ Universidade Anhanguera, Campo Grande, Mato Grosso do Sul, Brasil \\ paiva.izabela@gmail.com \\ Ademir Kleber Morbeck Oliveira \\ Universidade Anhanguera, Campo Grande, Mato Grosso do Sul, Brasil \\ akmorbeckoliveira@gmail.com \\ Vera Lúcia Ramos Bononi \\ Universidade Anhanguera, Campo Grande, Mato Grosso do Sul, Brasil \\ vbononi@uol.com.br
}

Artigo recebido em 11/08/2014 e aceito para publicação em 24/02/2015

RESUMO: Nesse momento de grande expansão da cultura de cana de açúcar e da agroindústria no Estado de Mato Grosso do Sul, o desenvolvimento de metodologias que permitam o acompanhamento e o monitoramento do meio socioeconômico pode contribuir para garantir a qualidade de vida de uma população em processo acelerado de mudanças. Empreendeu-se uma pesquisa junto ao Instituto de Meio Ambiente do Estado de Mato Grosso do Sul, no setor de Gerenciamento e Licenciamento Ambiental, na qual se deu a análise dos Estudos de Impacto Ambiental das usinas do setor sucroenergético que possuem licença de operação, visando diagnosticar a qualidade da abordagem socioeconômica. Foram analisados 17 EIAs, verificando-se que o trato do meio socioeconômico carece de um aprofundamento teórico-metodológico para avaliar satisfatoriamente os impactos deste setor sobre a população e suas implicações sobre a dinâmica das comunidades.

Palavras-Chave: Estudos socioeconômicos. Qualidade de vida. Avaliação de impactos ambientais.

ABSTRACT: The sugar cane cultivation and related industries expansion in the state of Mato Grosso do Sul, at this moment, is a challenge to the development of methodologies that will allow following and monitoring the socioeconomic environment, assuring life quality to local population under an accelerated process of changes. It was developed a search on the process of Environmental Impact Studies of sugar cane industries which own an Operation License, along with the Environmental Institute of Mato Grosso do Sul through the Management and Environmental Licensing Department, to diagnose the quality of social-economic approach. Seventeen Environmental Impact Studies were analyzed and it was noted that the utilized data are always secondary, there is no field research and the results demand theoretical and methodological definitions so they are able to evaluate correctly the impacts over the local population and their implications in communities dynamics. Keywords: Social-economic studies. Life quality. Environmental impact evaluation. 


\section{INTRODUÇÃO}

O Estado de Mato Grosso do Sul vivencia um momento de mudanças em sua matriz econômica. Segundo o Plano de Desenvolvimento Regional do Estado (MATO GROSSO DO SUL, 2009), tal fato se deve principalmente aos esforços empreendidos pelo governo estadual que, por meio de políticas públicas de desenvolvimento, fomenta a diversificação econômica, buscando atrair indústrias para agregar valor à produção interna, objetivando expandir os horizontes de exploração de suas cadeias produtivas potenciais. Nesse sentido, a cadeia do açúcar e do álcool tem contribuído positivamente para transpor as fronteiras de tradicional produtor e fornecedor de produtos primários, tal como a carne, e devido suas características edafoclimáticas, o Estado apresenta grande potencial para o desenvolvimento destas novas atividades.

Em sintonia com as tendências internacionais de mercado, as políticas públicas de desenvolvimento para a região abordam a preocupação com as questões socioeconômicas e ambientais, buscando atender aos princípios do desenvolvimento sustentável e é destacado que a observância das condições socioambientais na exploração dos recursos naturais será cada vez mais importante, não só para garantir o bem estar social, mas também para o acesso aos mercados consumidores nacionais e internacionais, com a sustentabilidade utilizada como fator condicionante para impulsionar um novo paradigma de desenvolvimento no Estado (MATO GROSSO DO SUL, 2009).

De acordo com Sachs (2009), o crescimento econômico é condição necessária para que o desenvolvimento sustentável seja possível, pois é fundamental que haja viabilidade econômica; no entanto, ele não é o objetivo em si na discussão da sustentabilidade, mas sim o instrumento para alcançar o desenvolvimento includente e sustentável.

Capra (2004) demonstra que o processo para se atingir um ambiente em que a sustentabilidade faça parte do crescimento econômico está relacionada a um complexo padrão de organização, que apresenta cinco características básicas: interdependência, reciclagem, parceria, flexibilidade e diversidade, encontradas nos ambientes naturais. O mesmo autor sugere que estes aspectos, quando aplicados às sociedades humanas, podem levar à sustentabilidade, que seria um processo que combina estas variáveis com a preocupação em não comprometer os recursos naturais, preservando o ambiente.

Segundo Schlesinger (2008), o discurso econômico e ambiental empregado pelo poder público para justificar os empreendimentos sucroenergéticos denotam apenas as características positivas do setor, geralmente desconsiderando os problemas que podem decorrer dessa atividade, como a geração ou agravamento de problemas sociais, tais como pressão sobre a infra-estrutura pública, desarticulação de produção local pela alteração da matriz econômica, desestabilidade econômica regional, entre outros que podem comprometer as condições e a qualidade de vida da população.

Por ser uma atividade potencialmente impactante etendo em vista o crescimento exponencial do setor sucroenergético no Estado de Mato Grosso do Sul, faz-se necessário garantir que o licenciamento ambiental e o monitoramento dessa cadeia sejam feitos de forma efetiva e eficaz, garantindo que os impactos positivos sejam maximizados, acarretando benefícios reais para a sociedade, e que os impactos negativos sejam mitigados, não incorrendo no que Sachs (2009) denominou desenvolvimento perverso, acarretando em grandes prejuízos sociais, econômicos e ambientais.

Com o objetivo de prevenir ou minorar os impactos negativos, além de tentar propiciar condições para que o desenvolvimento seja feito sem a posterior degradação ambiental, a legislação ambiental brasileira enquadrou as atividades do setor sucroenergético como potencialmente impactantes. Consequentemente, seus empreendimentos são submetidos à Avaliação de Impacto Ambiental AIA, por força da Lei 6.938/81, que institui a Política Nacional do Meio Ambiente - PNMA (BRASIL, 1981), e das resoluções do Conselho Nacional de Meio Ambiente - CONAMA 001/86 e 237/97 (BRASIL, 1986; 1997). AAIA se dá por meio do Licenciamento Ambiental, que tem o Estudo de Impacto Ambiental e o Relatório de Impacto Ambiental - EIA/RIMA, como principal instrumento. 
De acordo com o art. $6^{\circ}$ da Resolução 001/86 do Conselho Nacional do Meio Ambiente, o ambiente é um sistema dinâmico e interdependente de interações físico-bióticas e sociais. Nesse sentido, a legislação ambiental brasileira determinou que os estudos referentes à população humana fossem incorporados na avaliação de impactos ambientais de projetos potencialmente impactantes, orientando para uma abordagem que considerasse efetivamente as relações entre a sociedade e os recursos naturais.

Conforme Contador (1997), os efeitos diretos e indiretos dos danos ambientais interferem direta e indiretamente na qualidade de vida do homem. Assim, um mesmo projeto pode ser excelente sob o ponto de vista privado, embora péssimo sob o ponto de vista ambiental, e consequentemente, sob o ponto de vista social e vice-versa.

O estudo dirigido pelo Status of Women Council of the Nwt (2006) destacou a importância dos estudos socioeconômicos no contexto da avaliação de impactos ambientais, pois o diagnóstico desse meio permite dizer como o projeto poderá afetar social e economicamente as condições de vida das pessoas e das comunidades.

Segundo Glasson (2009), os estudos socioeconômicos são importantes porque as pessoas e seus modos de vida, suas culturas, suas economias e seus valores são fundamentais, sendo necessário conhecer de que maneira um projeto, seja ele público ou privado, pode afetar a estrutura das relações socioeconômicas das pessoas e comunidades.

Santos (2009), fazendo uma correlação entre a expansão da monocultura da cana e seus impactos, escreve que a instalação deste tipo de atividade muitas vezes está relacionada ao trabalho degradante nos canaviais, com reflexos negativos para o ambiente e saúde dos trabalhadores e moradores do entorno das áreas de plantio, resultado de estudos socioeconômicos que não abordaram adequadamente a questão.

Ao estudar o crescimento e a intensificação da presença do setor sucroenergético no Estado de São Paulo e seus efeitos sobre o bem estar social das comunidades locais, Liboni e Cezarino (2012) constataram que o setor impacta a população tanto de forma positiva, gerando benefícios diretos e indiretos sobre o emprego, desenvolvimento tecnológico e mesmo para posicionamento geopolítico do Brasil no cenário internacional, como de forma negativa, incorrendo em efeitos deletérios sobre o ambiente, o uso da terra e consequentemente, sobre o bem estar da comunidade local.

Estudos da Empresa Brasileira de Pecuária e Agricultura, Setor de Monitoramento por Satélite (EMBRAPA, 2010, p.4), que monitora e avalia os impactos advindos da cana-de-açúcar desde 1984, demonstraram que "a avaliação do impacto ambiental do sistema de produção da cana-de-açúcar não foi realizada de forma completa, ainda que em caráter piloto, em nenhum lugar no Brasil". Também considera que "as conseqências das mudanças acarretadas pelo setor sucroenergético sobre o ambiente e a socioeconomia das regiões atingidas direta ou indiretamente, apesar de sua magnitude e importância para o país, ainda são globalmente desconhecidas".

O Anuário Estatístico da Agroenergia do Ministério da Agricultura, Pecuária e Abastecimento (MAPA, 2009), demonstrou que o Brasil processou mais de 600 milhões de toneladas de cana de açúcar na safra 2009/2010. Comparando os dados da safra 2000/2001 com os dados de 2009/2010, notase como foi expressivo o crescimento da cadeia sucroenergética no Estado de Mato Grosso do Sul nesta última década, com valores de cana moída, safra 2000/01, 6.520 t, safra 2009/10, 23.297.819 t, álcool (anidro e hidratado), safra 2000/01 314.780 $\mathrm{m}^{3}$, safra 2009/10, 1.267.632 $\mathrm{m}^{3}$ e açúcar, safra 2000/01, 231.674 t, safra 2009/10, 746.761 t.

A década de 2000 foi a mais expressiva para a expansão do setor, que cresceu 418,61\% neste período, contra um crescimento de 246,74\% observado no Estado de São Paulo, $1^{\circ}$ lugar no ranking nacional de produção e processamento de cana de açúcar. Tal conjuntura indica a região Centro-Oeste como uma possível fronteira de expansão da cadeia da cana de açúcar no território brasileiro.

Moreira (2008), ao empreender uma análise prospectiva do padrão de expansão do setor sucroenergético no Brasil constatou, em relação ao emprego e renda, que o aumento percentual mais expressivo nos últimos anos se deu no Estado de Mato 
Grosso do Sul. Dados da Federação das Indústrias de Mato Grosso do Sul (FIEMS, 2011) demonstraram que essa cadeia gerou cerca de 26 mil postos de trabalhos nos últimos quatro anos, representando quase $5 \%$ da mão de obra empregada pela indústria sul-mato-grossense.

Nesse momento, de grande expansão da cultura de cana de açúcar e da agroindústria no Estado de Mato Grosso do Sul, o desenvolvimento de metodologias que permitam o acompanhamento e o monitoramento do meio socioeconômico pode contribuir para garantir a qualidade de vida de uma população em processo acelerado de mudanças. Desta maneira, o presente artigo tem como objetivo verificar se estudos socioeconômicos tem sido adequados para avaliar o bem estar da sociedade, aferindo a qualidade da abordagem deste meio no contexto do licenciamento ambiental de usinas sucroenergéticas no Estado.

\section{MATERIAIS E MÉTODOS}

Para fundamentar o trabalho, tomou-se como referência autores que consideram a questão social no contexto da avaliação de impactos ambientais, tais como Contador (1997), Buvinich (1999), Sousa (2000), Brusek, (2003), Ministério Público da União (2004), Coelho (2005), Sousa Junior et al. (2005), Honorato (2008), Moreira (2008), Sánchez (2008), Schlesinger (2008), Glasson (2009), Status Of Women Council Of The Nwt (2011) e Liboni e Cezarino (2012), entre outros.

Os dados foram levantados no Instituto de Meio Ambiente do Estado de Mato Grosso do Sul IMASUL, setor de Gerenciamento e Licenciamento Ambiental - GLA, no qual se deu a análise dos Estudos de Impacto Ambiental das usinas do setor sucroenergético, protocolados neste órgão até o primeiro semestre do ano de 2011, visando diagnosticar como a abordagem socioeconômica é apresentada no processo de licenciamento ambiental das usinas de álcool e açúcar.

Avaliou-se o número de usinas existentes e a fase do licenciamento ambiental em que se encontravam, obtendo-se o número de 45 unidades sucroenergéticas licenciadas e/ou em processo de licenciamento, sendo que: 19 estão na fase de licença prévia - LP, 9 na fase de licença de instalação - LI e 17 possuem licença de operação - LO.

Definiu-se trabalharcomos empreendimentos que possuem LO por entender que os processos de licenciamento ambiental dessas unidades estão concluídos e que todas as propostas de controle e monitoramento contidas no EIA foram validadas pela equipe de avaliação da GLA. A localização dos empreendimentos selecionados para o estudo possui maior concentração na região centro-sul do Estado.

Nos 17 processos selecionados, analisou-se o termo de referência e os itens nele especificados para composição do capítulo referente à socioeconomia, sendo: alternativas locacionais e áreas de influência; diagnóstico ambiental da área de influência do projeto; previsão e avaliação dos impactos ambientais; medidas mitigadoras e programas de acompanhamento e monitoramento. Em relação ao item diagnóstico socioeconômico, observouse a contemplação das exigências apresentadas no Quadro 1. 
Quadro 1. Instruções técnicas para elaboração do Diagnóstico Socioeconômico dos Termos de Referência emitidos pelo IMASUL (2011) para EIA’s de Empreendimentos Sucroenergéticos

\begin{tabular}{|c|c|}
\hline $\begin{array}{l}\text { P o p u } 1 \text { a ç ã o } \\
\text { humana }\end{array}$ & $\begin{array}{l}\text { Dimensionamento e caracterização social e econômica da população rural e urbana, } \\
\text { destacando aquela a ser direta e/ou indiretamente atingida pelo empreendimento; } \\
\text { caracterização dos principais núcleos populacionais urbanos e rurais no entorno do } \\
\text { empreendimento; identificação e caracterização das reservas e populações indígenas } \\
\text { existentes na área de influência do empreendimento. }\end{array}$ \\
\hline $\begin{array}{l}\text { E s t r u t u r a } \\
\text { produtiva } \\
\text { e de serviços }\end{array}$ & $\begin{array}{l}\text { Caracterização da estrutura dos serviços primário, secundário e terciário; caracterização } \\
\text { das atividades agropecuárias, industriais, comerciais e de serviços; caracterização fundiária } \\
\text { das propriedades diretamente atingidas, incluindo a descrição de posse, uso e benfeitorias } \\
\text { das terras. }\end{array}$ \\
\hline & $\begin{array}{l}\text { Oferta de serviços (saúde, abastecimento d'água, etc.) e outras informações julgadas } \\
\text { necessárias. }\end{array}$ \\
\hline $\begin{array}{l}\text { Infra-estrutura } \\
\text { regional }\end{array}$ & $\begin{array}{l}\text { Caracterização do sistema viário, abrangendo rodovias, ferrovias, hidrovias e aeroportos; } \\
\text { caracterização do sistema de transmissão e distribuição de energia elétrica; caracterização } \\
\text { do sistema de telecomunicações; mapas com a infra-estrutura regional. }\end{array}$ \\
\hline Uso do solo & $\begin{array}{l}\text { Identificação, em planta em escala adequada, das interferências do projeto com os } \\
\text { sistemas viários e de transportes, linhas de transmissão de energia, oleodutos, gasodutos, } \\
\text { disposição de resíduos, etc.; delimitação, em escala adequada, dos principais usos do } \\
\text { solo (residencial, industrial, agrícola, etc.); indicações que possam esclarecer a situação } \\
\text { atual da área; identificação e caracterização das principais indústrias existentes na área } \\
\text { de influência, tipo de tratamento dado aos efluentes, localização de lançamento e vazão, } \\
\text { indicando-se a proximidade com a área do empreendimento. }\end{array}$ \\
\hline
\end{tabular}

Fonte: Secretaria de Estado de Meio Ambiente, do Planejamento, da Ciência e Tecnologia - Semac, 2009 (adaptada).

\section{RESULTADOS E DISCUSSÃO}

\section{Termo de Referência}

A análise dos documentos referentes aos processos de licenciamento ambiental indicou que todos os estudos seguiram o mesmo termo de referência, sem considerar as especificidades de cada região do Estado onde os empreendimentos pleiteavam as licenças. Os termos de referência emitidos limitavam-se a exigir basicamente os itens já previstos no art. $6^{\circ}$ da Resolução CONAMA 001/86.

O termo de referência é um instrumento emitido pelo órgão licenciador para orientar sobre os estudos necessários para a avaliação de impactos de determinado empreendimento numa localidade específica. A Resolução CONAMA 001/86, em seu artigo $5^{\circ}$, Parágrafo Único, explicita que compete ao órgão ambiental fixar as diretrizes adicionais que, pelas peculiaridades do projeto e características ambientais da área, se julguem necessárias. Segundo o Ministério Público da União (2004, p. 11), o termo de referência "fornece a moldura teórico-metodológica e as diretrizes temáticas, por intermédio das quais a inserção regional e as alternativas conceituais do projeto serão descritas e avaliadas, indiretamente, o termo de referência também define o perfil da equipe técnica".

Para Sanchéz (2008, p.135), o termo de referência é fundamental na avaliação de impactos, pois é este instrumento que define a abrangência e o escopo do trabalho, orientando para uma avaliação de impactos significativos no contexto analisado.

Dessa forma, para que o termo de referência seja um instrumento efetivo e eficaz, ele deve ser elaborado considerando as características do empreendimento e da região onde ele será implantado, 
compreendendo cenários específicos e únicos, acarretando que cada EIA seja capaz de avaliar os impactos relevantes em cada situação específica, devido suas particularidades.

A Resolução SEMAC N.008, de 31 de Maio de 2011 (MATO GROSSO DO SUL, 2011), que regulamenta o processo de licenciamento ambiental no Mato Grosso do Sul, institucionalizou um termo de referência único para os estudos de empreendimentos sucroenergéticos, não sendo mais necessária a análise das características dos projetos nem das regiões a serem impactadas para a emissão deste documento.

Não obstante, nota-se que esses empreendimentos estão localizados em diferentes regiões do Estado (Norte, Leste e Centro-Sul) e, possuem características ambientais distintas e que, portanto, apresentam dinâmicas sociais particulares de modos de vida. Assim, a utilização do mesmo termo de referência pode ter limitado os estudos, podendo comprometer a avaliação dos diferentes impactos ocorridos em relação ao meio socioeconômico.

Observou-se ainda que nenhum dos termos analisados indicou as abordagens teóricometodológicas mínimas a serem utilizadas para o meio socioeconômico, sendo que a sua escolha ficou sempre a cargo das equipes técnicas de cada EIA. Como conseqüência, observou-se uma variedade muito grande de metodologias de análise empregadas para a contemplação das exigências do termo de referência, dificultando uma comparação entre os resultados de todos os estudos analisados.

Verificou-se que os termos de referência estabeleciam o número de páginas máximo para a contemplação de cada meio e de cada item, sendo reservadas 10 páginas para o diagnóstico do meio socioeconômico, o que pode ter, minimamente, limitado os estudos realizados, comprometendo sua qualidade.

$\mathrm{Na}$ intenção de aperfeiçoar seu sistema de licenciamento ambiental, as medidas adotadas em relaçãoaostermos dereferênciapodem provavelmente resultar em prejuízos para a qualidade da Avaliação de Impactos Ambientais do setor sucroenergético.

\section{Definição das Áreas de Influência}

A análise dos dados revelou que a única orientação do termo de referência para a definição das áreas de influência - AI é aquela expressa no artigo $5^{\circ}$ da Resolução CONAMA 001/86, que orienta a equipe a considerar minimamente a área geográfica da bacia hidrográfica na qual se localiza o empreendimento.

Segundo o Ministério Público Federal (2004, p.17), as áreas de influência delimitam a abrangência espacial dos possíveis impactos decorrentes das intervenções ambientais necessárias para a implantação do projeto, em todas as suas fases. A correta definição dessas áreas é de extrema importância, pois determina os espaços onde incidirão os programas e/ou medidas de mitigação ou compensação.

De acordo com Sánchez (2008), somente após a previsão dos impactos é que se pode tirar alguma conclusão sobre a área de influência do empreendimento proposto. Desta maneira, ela não poderia ser estabelecida de antemão, ou seja, antes de se iniciarem os estudos, exceto como hipótese a ser verificada, devendo ser delimitada para cada fator ambiental natural e também para os componentes culturais, econômicos, sociais e políticos, além de apresentar os critérios que determinam tais áreas.

Porém, não se constatou em nenhum dos termos de referência, utilizados para elaboração dos estudos analisados, orientações específicas para a delimitação das áreas de influência sobre o meio socioeconômico que levassem em conta as relações de uso e ocupação do solo, as relações de valores e sentimentos referidos a lugares ou as relações de dependência entre a sociedade local e os recursos ambientais.

Não havendo uma orientação mínima a ser seguida para a delimitação das AIs do meio socioeconômico encontrou-se, entre os EIAs pesquisados, diferentes delimitações para as áreas a serem estudadas, tanto das Áreas de Influência Direta - AIDs, quanto das Áreas de Influência Indireta AIIs. Os raios estipulados para delimitar o alcance dos impactos diretos dos empreendimentos variaram desde a área da planta industrial, sem considerar 
sequer o entorno imediato dela, até um raio de $50 \mathrm{~km}$, utilizando-se provavelmente do dimensionamento da área de lavoura necessária para abastecimento do empreendimento.

As áreas de influência indireta para o meio socioeconômico foram definidas como compreendendo desde a extensão territorial do município sede do empreendimento até a área de um ou mais municípios circunvizinhos. Apenas quatro trabalhos apresentaram alguma justificativa ou critério utilizado para a definição das áreas de influência dos projetos.

Verificou-se que a falta de orientações ou exigências mínimas para a delimitação das áreas de estudo e áreas de influência dos EIAs analisados, em relação à socioeconomia, influenciou diretamente na elaboração dos diagnósticos socioeconômicos, não permitindo uma análise profunda do meio social e das suas inter-relações com o meio biofísico, e, portanto, interferindo na qualidade da previsão de impactos e na proposição dos programas de monitoramento.

\section{Diagnóstico Socioeconômico}

Segundo o Ministério Público da União (2004), embora seja impossível predizer com exatidão absoluta, os impactos de um empreendimento, sua previsão e dimensionamento pode ser realizada a contento desde que se disponha de elementos resultantes de um bom diagnóstico, baseado em modelos adequados de análise interdisciplinar.

Se o diagnóstico socioeconômico retrata a realidade de forma distorcida ou incompleta, as demais ações co-relacionadas e interdependentes dele estarão igualmente comprometidas. Considerandose as deficiências anteriormente observadas e discutidas, pode-se atestar que as caracterizações socioeconômicas empreendidas nos estudos analisados estão no mínimo, incompletas, com omissão ou descrição insuficiente da metodologia aplicada para a composição do diagnóstico. De acordo com o Ministério Público da União (2004, p. 21) "a ausência de suficiente explicação metodológica dificulta a análise do EIA, uma vez que não permite inferir sobre a representatividade dos dados".

Segundo Coelho (2005, p. 20) "as análises ambientais falham, devido principalmente à falta de profundidade teórica e ao seu reduzido poder explicativo". A referida autora afirma ainda que "a ausência de teorias dos processos sociais implica a superficialidade da compreensão do social e das suas inter-relações com o meio biofísico" e assim torna-se muito difícil diagnosticar de forma eficiente as implicações dos impactos ambientais sobre a qualidade de vida das comunidades afetadas.

Verificou-se que a subjetividade metodológica aplicada para o desenvolvimento dos diagnósticos dificulta ou até mesmo impossibilita uma análise da representatividade dos dados compilados em cada estudo. A mesma problemática já havia sido observada pelo Ministério Público da União (2004), que constatou que as deficiências encontradas nas abordagens socioeconômicas no contexto do Estudo de Impacto Ambiental se referem a pesquisas insuficientes e metodologias ineficazes para a descrição e compreensão dos modos de vidas locais e suas interações com o ambiente.

Outro aspecto observado em relação ao diagnóstico socioeconômico foi a contemplação parcial e/ou insuficiente de determinadas exigências apresentadas no termo de referência. A análise dos dados indicou que os itens relacionados ao dimensionamento e caracterização social da população urbana e rural a serdiretae/ou indiretamente atingida pelo empreendimento e a identificação e caracterização das reservas e populações indígenas existentes na área de influência do empreendimento foram baseadas em fonte de dados secundários. Em nenhum dos trabalhos observou-se acréscimo ao conhecimento disponível sobre os modos de vida de coletividades socioculturais nos contextos estudados, o que compromete a previsão e avaliação dos impactos dos empreendimentos sobre a população.

A mesma situação foi observada pelo Ministério Público da União (2004, p. 28), verificando que o diagnóstico do meio socioeconômico resumese a "caracterizações socioeconômicas regionais genéricas, não articuladas a pesquisas diretas locais". Em todos os estudos a informação sobre a dinâmica sociocultural e econômica das comunidades se deu de forma generalizada, não tendo sido empregados esforços para sua interpretação ou co-relação dessas 
informações com a dinâmica social das áreas de estudo e com as atividades do projeto, o que teria sido possível a partir do levantamento de dados primários.

De um modo geral, as informações apresentadas nos diagnósticos socioeconômicos referem-se principalmente à população da Área de Influência Indireta, sobre a qual se têm maior disponibilidade de informações estatísticas e bibliográficas. Apenas quatro trabalhos apresentaram pesquisas de campo. Assim, as informações prestadas em relação àquelas exigidas pelo termo de referência resumiram-se basicamente a uma compilação de dados estatísticos e bibliográficos, mesclados com informações infimamente resumidas que nada revelam sobre a teia de relações sociais estabelecida pela população que será afetada pelas ações do empreendimento, principalmente aquela localizada no entorno das áreas diretamente afetadas pelos projetos.

Pode-se constatar que as abordagens socioeconômicas apresentadas nos estudos analisados apresentaram deficiências teórico-metodológicas e científicas que implicaram no comprometimento da delimitação das áreas de estudo e, consequentemente, comprometimento das análises necessárias para atendimento efetivo e eficaz do termo de referência. Observou-se ainda que não foi realizada uma análise integrada das informações levantadas, sendo que não estabelecem relação alguma com os demais meios de estudo abordados, como pressupõe as orientações da Resolução CONAMA 001/86. Os estudos apresentados não revelaram satisfatoriamente as relações entre a sociedade e os recursos ambientais de que ela dispõe e com os quais ela interage.

Conforme Coelho (2005), articular num mesmo modelo as análises dos processos naturais e sociais se constitui num dos desafios impostos à avaliação de impactos ambientais. No entanto, para que a avaliação de impactos seja efetiva e eficaz, é fundamental reconhecer que a sociedade faz parte do ambiente e que, compreender os princípios de sua estruturação é fundamental para uma compreensão dos processos que resultam em impactos ambientais.

\section{Identificação e Avaliação de Impactos Ambientais}

A pesquisa permitiu atestar uma série de deficiênciasno processodeidentificaçãoe avaliação de impactos sobre o meio socioeconômico, decorrentes das lacunas deixadas nas etapas anteriores. Em 13 dos 17 estudos analisados, observou-se que os impactos foram descritos superficialmente e não revelam a fundo suas implicações sobre a dinâmica social, cultural e econômica das comunidades afetadas pelos empreendimentos sucroenergéticos.

Segundo Sánchez (2008), a avaliação de impactos implica numa interpretação consistente das relações ecológicas e das interações sociais, não se resumindo a simples identificação dos impactos, e que por essa razão, só é possível se calcada em estudos de base consistentes, que fornecerão os elementos necessários para que as previsões sejam devidamente fundamentadas. Uma das razões para as deficiências no processo de avaliação de impactos consiste na dificuldade de incorporar a essas análises implicações resultantes da relação dinâmica entre sociedade e natureza. Tais implicações deveriam constar no capítulo referente ao diagnóstico socioeconômico que é o espaço adequado para revelar as imbricações da complexa relação entre sociedade e ambiente (COELHO, 2005).

Dessa maneira, para que a equipe técnica possa realizar a avaliação de impactos, ela deve considerar o projeto construtivo do empreendimento, localizando as áreas a serem ocupadas pela indústria e de lavoura a serem fertirrigadas, de modo a deflagrar as intervenções necessárias sobre o ambiente. Confrontando essas informações com aquelas derivadas do diagnóstico socioeconômico, seria possível avaliar as implicações sobre as condições e qualidade de vida das comunidades afetadas. Dessa forma, a equipe teria o subsídio necessário para identificar e avaliar os impactos sobre a sociedade nas diferentes áreas de influência delimitadas no EIA.

No setor sucroenergético, existem basicamente duas situações a serem consideradas na identificação e avaliação de impactos ambientais: áreas do parque industrial e as de lavoura de cana-de- 
açúcar. São nestes dois cenários que se concentram as ações da cadeia que causam intervenções no meio, produzindo externalidades negativas e positivas que se expandem às áreas de influência, interferindo direta e indiretamente nas condições e qualidade de vida das pessoas.

Segundo Coelho (2005, p.25), para que se possa entender ecaracterizarum impacto, énecessário, antes de tudo, aplicar esforços para compreender a história da sua produção, pois o impacto ambiental não é apenas resultado de uma determinada ação realizada sobre o ambiente: é a relação de mudanças sociais e ecológicas em movimento.

Verificou-se que a análise de impactos de 12 EIAs não contemplava externalidades negativas reconhecidamente relacionados à cadeia sucroenergética como, por exemplo, incômodos gerados à população advindos do odor proveniente das lagoas de vinhaça ou da fertirrigação, problemas relacionados à queima dos canaviais, ou doenças respiratórias correlacionadasàs emissõesatmosféricas advindas das diferentes atividades relacionadas ao plantio e processamento da cana-de-açúcar.

Segundo os estudos de Sousa (2000), Sousa Junior et al. (2005) e Honorato (2008), que abordam os impactos socioeconômicos de grandes projetos de investimentos, alguns critérios devem ser analisados, tanto nos estudos ambientais quanto nos programas de monitoramento, como por exemplo: mudanças nas interações sociais cotidianas; transformações no estilo de vida; perda de valores e sentimentos referidos a lugares; deslocamento da população residente no entorno; alteração do padrão da população urbana e rural; riscos de incêndio; risco de acidente de trabalho; problemas sociais como, prostituição, gravidez precoce, alcoolismo, aumento da criminalidade, alteração na matriz econômica dos municípios; especulação imobiliária; elevação do custo de vida; transformações no mercado de trabalho; desequilíbrio entre oferta e procura de bens e serviços no comércio; transformações no comportamento do consumidor; abertura de novos mercados; transformações na economia primaria e terciária; alteração e perda de sistemas agropecuários; pressões sobre o uso do solo; diminuição de pequenos produtores; surgimento de economia marginal/ informal; endividamento; pauperização; entre outros problemas.

Aliado a isso, verificou-se a subutilização ou desconsideração dos dados apresentados nos diagnósticos; isto porque os impactos descritos não possuem relação com as análises empreendidas nos diagnósticos. Observou-se que em 12 dos 17 estudos analisados não foram considerados os indicadores utilizados para caracterizar a população estudada na identificação e valoração dos impactos para este meio, a começar pelo subdimensionamento ou desconsideração das áreas de influência na localização dos impactos.

Constatou-sequeem 13 dosestudosanalisados as áreas de influência não foram consideradas de forma satisfatória, uma vez que a análise dos impactos não se ateve a essa delimitação. A pesquisa demonstrou que em 12 dos 17 estudos analisados, a identificação e localização dos impactos negativos se deu de forma aglomerada, ou seja, em áreas próximas aos empreendimentos, onde se pressupõe que a aplicação das medidas mitigadoras se daria de forma mais conveniente e menos dispendiosa para o empreendedor. Quanto aos impactos positivos, foram localizados de forma dispersa em todos os estudos, atingindo, em diferentes níveis, todas as áreas propostas, quando não extrapolando-as.

Observou-se que em 10 dos estudos analisados a qualificação dos impactos identificados tendeu a minimizar ou subestimar os impactos negativos e a supervalorizar os impactos positivos, de forma a sustentar uma análise positiva à viabilização do projeto sob o aspecto socioeconômico.

Ocorre que os impactos positivos da cadeia sucroenergética, tais como geração de emprego e renda e dinamização das economias locais, são utilizados como justificativa maior para a implantação dos empreendimentos do setor. Certamente, tais impactos são muito relevantes e tem contribuído significativamente para o crescimento econômico do Estado. No entanto, não podem se sobrepor aos demais impactos advindos dessa atividade, como aqueles elencados por Sousa (2008), Sousa et al. (2005) e Honorato (2008).

Verificou-se que em nenhum dos estudos pesquisados foi realizada uma análise 
da cumulatividade e sinergia dos impactos socioeconômicos advindos da atividade sucroenergética, nem em âmbito local, nem em âmbito regional. A resolução CONAMA 001/86, em seu artigo $6^{\circ}$, deixa claro que deverão ser consideradas as propriedades cumulativas e sinérgicas dos impactos.

Conforme Ministério Público da União (2004, p.33) "uma avaliação de efeitos ambientais deve considerar a cumulatividade e a sinergia dos impactos, uma vez que a associação de várias intervenções pode agravar ou mesmo gerar problemas sociais que, de outro modo, não ocorreriam". Observando-se a distribuição espacial das unidades sucroenergéticas em análise no Estado, pode-se afirmar que os impactos dessa cadeia serão mais intensos na região Centro-Sul, que concentra o maior número de empreendimentos, 17 no total.

Desconsiderar esta questão significa desconsiderar os efeitos conjuntos da cadeia sucroenergética sobre a socioeconomia e dessa forma, impossível atestar se esta é ou não uma atividade capaz de promover o desenvolvimento sustentável, como prevê o Plano de Desenvolvimento Regional (MATO GROSSO DO SUL, 2009). Neste contexto, é fundamental que se faça uma avaliação de impactos ambientais onde se considere a sinergia e cumulatividade dos impactos advindos da atividade sucroenergética na região.

Ainda em relação à identificação e avaliação de impactos, verificou-se que, à revelia das orientações dos termos de referência, apenas quatro estudos consideraram a opinião popular acerca do empreendimento. A pesquisa desenvolvida pelo Ministério Público da União (2014, p.32) demonstrou que "os responsáveis pela elaboração dos Estudos, em geral, não promovem a adoção de métodos participativos desde as primeiras pesquisas, de modo à melhor considerar experiências coletivas e individuais dos próprios afetados e de seus movimentos representativos.".

Pôde-se constatar também que a avaliação de impactos não se deu sob uma perspectiva interdisciplinar, como orienta a Resolução CONAMA 001/86, mas sim de forma segregada, deflagrando a ausência de uma análise integrada, tanto na identificação quanto na valoração dos impactos elencados. Por exemplo: em todos os trabalhos pesquisados, a alteração da qualidade do ar foi identificada e descrita como um impacto referente ao meio físico, sendo que as medidas mitigadoras propostas para este impacto resumem-se ao controle dos níveis de emissões atmosféricas conforme os padrões de qualidade do ar estabelecidos pelo CONAMA. Apenas quatro trabalhos consideraram as implicações desse impacto sobre a população humana, mas, mesmo nesses casos, na descrição das medidas mitigadoras, não foram considerados como indicadores os dados apresentados nos diagnósticos socioeconômicos, como as informações referentes às condições de saúde da população estudada.

Vê-se claramente que este é um impacto do meio físico, porém, com grande influência sobre a população; no entanto, em nenhum dos EIAs foi mencionada qualquer questão referente à saúde das pessoas correlacionada às emissões atmosféricas. $\mathrm{Da}$ mesma forma, não foram mencionados os impactos diretos e/ou indiretos dos ruídos advindos das atividades do empreendimento sobre a saúde dos trabalhadores ou da população das áreas de influência.

\section{Medidas Mitigadoras e Maximizadoras}

A Resolução CONAMA 001/86 preconiza que sejam propostas medidas para minimizar ou anular os impactos previstos. Ao longo deste estudo, observou-se que as medidas propostas para a mitigação dos impactos sobre o meio socioeconômico se restringiram basicamente à área diretamente afetada, que consistiria no desenvolvimento de ações junto aos colaboradores sob responsabilidade do empreendedor.

Na maioria dos casos analisados, as medidas propostas não tinham capacidade para mitigar ou reverter qualquer processo, com cerca de $70 \%$ das medidas propostas apresentando características que se aproximaram mais à compensação que à mitigação de externalidades negativas. Por exemplo, o uso de equipamentos de proteção individual, por parte dos colaboradores foi descrita como uma medida mitigadora; no entanto, trata-se de atendimento à legislação trabalhista.

Em relação aos impactos positivos, a medida 
maximizadora que se repetiu em todos os estudos analisados foi a intenção de contratar mão de obra local e regional para preencher o quadro de funcionários das empresas, o que acarretaria na dinamização das economias locais e regional. Esta é, inclusive, uma das principais prerrogativas utilizadas para justificar os empreendimentos sucroenergéticos no Estado.

No entanto, a contratação de mão de obra não se limita à vontade do empreendedor: na verdade, está atrelada a uma série de condicionantes como, disponibilidade e qualificação da mão de obra disponível, entre outros fatores. Ocorre que, no Estado, este impacto positivo tem se concretizado em função das parcerias estabelecidas entre o poder público e a iniciativa privada, que têm promovido a capacitação de mão de obra para atender o setor, em função da necessidade do mercado em atender à demanda criada e não somente porque essa medida maximizadora tenha sido proposta nos EIAs.

\section{Proposição dos Programas de Monitoramento}

De acordo com Buvinich (1999, p.20), “o monitoramento fornece a informação e as sugestões necessárias para que a gerência do programa verifique o progresso da implementação, a fim de tomar as decisões cabíveis, no sentido de que as metas programadas sejam alcançadas e/ou ajustadas". Segundo Bastos e Almeida (2010), os programas de monitoramento têm por objetivo monitorar as ações estabelecidas para a proteção do ambiente e mitigação dos impactos negativos, bem como das ações para incrementar os impactos positivos, incluindo ainda programas para situação de emergência e de acidentes.

O monitoramento ambiental, que tem caráter preventivo, permite identificar a materialização de impactos não previstos pelo EIA ou impactos com magnitude maior que a prevista; possibilita também a verificação de impactos materializados pela ineficiência das medidas mitigadoras, ou no caso dos impactos positivos, a não manifestação desses impactos. Em todos os casos, o monitoramento adequado permite a identificação do problema em tempo hábil para seu controle e correção, evitando que os impactos se efetivem, ou que se tornem de difícil reversibilidade ou até mesmo irreversíveis.
Por essa razão Almeida e Tertuliano (2010) afirmaram que um produto necessário dos estudos de monitoramento é a elaboração de planos de contingência, abarcando estratégias e prioridades para proteção dos fatores ecológicos e econômicos. Verificou-se que nenhum programa de monitoramento apresentou medidas para situações de emergência ou acidentes.

Constatou-se que os programas de monitoramento propostos para o meio socioeconômico não apresentam características necessárias para acompanhar ou monitorar os impactos previstos. Os programas apresentados referem-se a práticas que são obrigatórias ao empreendedor, como por exemplo, o Programa de Segurança e Saúde do Trabalhador. Em nenhum dos EIA's analisados foram propostos programas de monitoramento das condições e ou qualidade de vida das populações afetadas pelas ações do empreendimento, em nenhuma de suas fases.

Observou-se que as propostas de monitoramento apresentadas para o meio socioeconômico resumem-se basicamente a programas de educação ambiental e de comunicação social que não apresentaram condições ou características para acompanhar as variações de condição e/ou qualidade de vida das comunidades direta e indiretamente afetadas. Desta forma não se pode aferir alterações (positivas ou negativas) sobre o bem estar social, e assim qualquer alteração sobre a socioeconomia não será identificada, sendo que provavelmente só será percebida quando estiver consolidada.

\section{CONSIDERAÇÕES FINAIS}

Diagnosticou-se deficiências em todas as etapas dos estudos analisados, a começar pelo termo de referência que induz a abordagens genéricas e de reduzido poder explicativo sobre os arranjos sociais. Verificou-se que a formação profissional dos técnicos e número reduzido de profissionais para a caracterização socioeconômica contribuiu para as deficiências identificadas no processo de avaliação de impactos sobre este meio, tanto no que diz respeito à falta de aprofundamento dos levantamentos quanto em relação aos problemas teórico-metodológicos identificados no decorrer da 
pesquisa, comprometendo a qualidade dos estudos.

Os trabalhos não abordam de forma consistente as relações entre a sociedade e os recursos naturais dos quais ela dispõe e com os quais ela interage. A omissão ou descrição insuficiente das metodologias utilizadas não permitem verificar a aplicabilidade ou representatividade dos resultados apresentados. Por essas razões, pode-se atestar que, de um modo geral, são desconhecidos os reais impactos da cadeia sucroenergética sobre a população do Estado. Dessa forma, não se evidencia o pressuposto de que o desenvolvimento desta atividade seja ambientalmente sustentável, como sugerem as políticas públicas de desenvolvimento.

No contexto da avaliação de impactos ambientais, o instrumento que permite observar as modificações decorrentes da operação das atividades sucroenergéticas sobre a sociedade, tanto positivas quanto negativas, são os programas de monitoramento. Como evidenciado na pesquisa, os programas propostos não têm qualquer relação com os indicadores previstos nos termos de referência e tampouco com o diagnóstico ambiental. Este fato inviabiliza a premissa de que tais empreendimentos tenham seus efeitos conhecidos sobre a sociedade envolvida direta e indiretamente com o setor. Como consequência, o acompanhamento real e concreto desses impactos ao longo do tempo torna-se ineficiente, perdendo a eficácia como ferramenta que permita a detecção de anomalias e a implantação de ajustes e correções.

Conclui-se que para que seja possível atestar a contribuição do setor sucroenergético para o desenvolvimento sustentável do Estado, no que se refere à socioeconomia, é necessário que a abordagem deste meio, no contexto do licenciamento ambiental, seja realizada com maior rigor técnico-científico e maior aprofundamento teórico-metodológico, permitindo avaliar satisfatoriamente os impactos deste setor sobre a população e suas implicações sobre a dinâmica das comunidades.

\section{REFERÊNCIAS}

ALMEIDA, J. R.; TERTULIANO, M. F. Diagnose dos sistemas ambientais: métodos e indicadores. In:
CUNHA, S. B.; GUERRA, A. J. T. (Org.). Avaliação e perícia ambiental. 10. ed. Rio de Janeiro: Bertrand Brasil, 2010. p. 115-170.

BASTOS, A. C. S.; ALMEIDA, J. R. Licenciamento ambiental brasileiro no contexto da Avaliação de Impactos Ambientais. In: CUNHA, S. B.; GUERRA, A. J. T. (Org.). Avaliação e perícia ambiental. 10. ed. Rio de Janeiro: Bertrand Brasil, 2010. p. 77-110.

BRASIL. Lei 6.938, de 31 de outubro de 1981. Dispõe sobre a Política Nacional do Meio Ambiente, seus fins e mecanismos de formulação e aplicação e dá outras providências. Diário Oficial [da] República Federativa do Brasil, Poder Executivo, Brasília, DF, 31 out. 1981.

BRASIL. Resolução CONAMA 001/86 de 01 de janeiro de 1986. Dispõe sobre os critérios básicos e diretrizes gerais para o Relatório de Impacto Ambiental. Diário Oficial [da] República Federativa do Brasil, Poder Executivo, Brasília - DF, 01 jan. 1986.

BRASIL. Resolução CONAMA 237/97 de 19 de dezembro de 1997. Regulamenta os aspectos de licenciamento ambiental estabelecidos na Política Nacional do Meio Ambiente. Diário Oficial [da] República Federativa do Brasil, Poder Executivo, Brasília, DF, 19 out. 2002.

BRUSEK, F. J. O problema do desenvolvimento sustentável. In: CAVALCANTI, C. (Org.). Desenvolvimento e natureza: estudos para uma sociedade sustentável. 4. ed. São Paulo: Cortez, 2003. p. 14-21.

BUVNICH, M. R. Ferramentas para o monitoramento e avaliação de programas e projetos sociais. Cadernos de Políticas Sociais, N. 10, 1999. (Série Documentos para Discussão)

CAPRA, F. A teia da vida: uma nova compreensão cientifica dos sistemas vivos. 9. ed. Trad. Newton Roberval Eichemberg. São Paulo: Editora PensamentoCultrix Ltda, 2004. 
COELHO, M. C. N. Impactos ambientais em áreas urbanas: teorias, conceitos e métodos de pesquisa. In: GUERRA, A. J. T.; CUNHA, S. B. C. (Org.). Impactos ambientais urbanos no Brasil. 3. ed. Rio de Janeiro: Bertrand Brasil, 2005. p. 19-43.

CONTADOR, C. R. Projetos sociais: avaliação e prática. 3. ed. São Paulo: Atlas, 1997.

EMBRAPA. Empresa Brasileira de Pesquisa Agropecuária. Impacto ambiental da cana-de-açúcar. Disponível em: < $\underline{w} w w . c a n a . c n p m . e m b r a p a . b r>$. Acesso em: 02 ago. 2010.

FIEMS. Federação das Indústrias do Estado de Mato Grosso do Sul. Mapa da indústria. Disponível em: $<$ http://www.fiems.org.br/novo/mapa-da-industria>. Acesso em: 25 ago. 2011.

GLASSON, J. Socio-economic impacts 1: overview and economic impacts. In: MORRIS, P.; THERIVEL, R. (Org.). Methods of environmental impact assessment. New York: Routledge, 2009. p. 22-50.

HONORATO, G. S. Gerenciando impactos sócioeconômicos: o papel da Sociologia na implementação de usinas hidrelétricas no Brasil. Revista Espaço Acadêmico, n. 86, p.1-6, 2008.

LIBONI, L. B.; CEZARINO, L. O. Impactos sociais e ambientais da indústria da cana-de-açúcar. Future Studies Research Journal, v.4, n.1, p.202-230, 2012. DOI: http://dx.doi.org/10.7444/fsrj.v4i1.101

MAPA. Ministério da Agricultura, Pecuária e Abastecimento. Anuário Estatístico da Agroenergia. Brasília, 2009. Disponível em: <http: //www. agricultura. gov.br/arq_editor / file/ Desenvolvimento_ Sustentavel/Agroenergia/anuario_agroenergia/index. html\#>. Acesso em: 10 set. 2011.

MATO GROSSO DO SUL. Plano de Desenvolvimento Regional de Mato Grosso do Sul PDR - MS 2030. Campo Grande, 2009.Disponívelem: $<$ http://www. semac.ms.gov. br $/$ index.php ?inside $=1 \&$ tp $=3 \&$ comp $=\&$ show $=3313>$. Acesso em: 26 out. 2011.
MATO GROSSO DO SUL. Resolução SEMAC N.008, de 31 de maio de 2011. Estabelece normas e procedimentos para o licenciamento ambiental Estadual, e dá outras providências. Diário Oficial [do] Estado de Mato Grosso do Sul, Poder Executivo, Campo Grande, MS, 02 mai. 2011.

MINISTÉRIO PÚBLICO DA UNIÃO. Deficiências em Estudos de Impacto Ambiental: síntese de uma experiência. Brasília: Ministério Público Federal, $4^{\mathrm{a}}$ Câmara de Coordenação e Revisão: Escola Superior do Ministério Público da União, 2004.

MOREIRA, M. M. R. Análise prospectiva do padrão de expansão do setor sucroenergético brasileiro: uma aplicação de modelos probabilísticos com dados georeferenciados. 2008. 151 f. Dissertação (Mestrado em Economia das Instituições e do Desenvolvimento) - Faculdade de Economia, Administração e Contabilidade, Universidade de São Paulo, São Paulo. 2008.

SACHS, I. Primeira parte. In: NASCIMENTO, E. P.; VIANNA, J. N. (Org.). Dilemas e desafios do desenvolvimento sustentável no Brasil. Rio de Janeiro: Garamond, 2009. p.21-41.

SÁNCHEZ, L. H. Avaliação de impacto ambiental: conceitos e métodos. São Paulo: Oficina de Textos, 2008. 495p.

SANTO, A. P. Natureza e trabalho na lógica do capital: contradições sociais do desenvolvimento econômico e limites ambientais do complexo agroindustrial canavieiro no Brasil. Revista Herramienta, n. 42, p. 91-107, 2009.

SCHLESINGER, S. Lenha nova para velha fornalha: a febre dos agrocumbustiveis. Rio de Janeiro: FASE, 2008.

SECRETARIA DE ESTADO DE MEIO AMBIENTE, DO PLANEJAMENTO, DA CIÊNCIA E TECNOLOGIA - SEMAC. Termo de Referência para Elaboração de Estudos de Impacto Ambiental do Setor Sucroenergético no Estado de Mato Grosso 
do Sul. MS: Instituto de Meio Ambiente do Estado de Mato Grosso do Sul - IMASUL, 2009.

SOUSA JUNIOR, W. C.; REID, J. L.; SILVESTRE, N. C. Custos e beneficios do complexo Hidrelétrico Belo Monte: uma abordagem econômico-ambiental. Relatório de Pesquisa. Belo Monte, 2005. Disponível em: $<$ http://www.ibcperu.org/doc/isis/8325> Acesso em: 11 mar. 2010.

SOUSA, W. L. Impacto ambiental de hidrelétricas: uma análise comparativa de duas abordagens. 2000. 160 f. Dissertação (Mestrado em Ciências em Planejamento Energético) -Coppe - Instituto Alberto Luiz Coimbra de Pós-Graduação e Pesquisa de Engenharia, Universidade Federal do Rio de Janeiro, Rio de Janeiro. 2000.

STATUS OF WOMEN COUNCIL OF THE NWT. $A$ 'How to Guide' for participating in socio-economic impact assessment in the NWT. Disponível em: $<$ http:// www. statusofwomen.nt.ca/download/SEIA_How To_Guide.pdf $>$. Acesso em: 10 fev 2011.19p. 